\title{
Questionnaires, spirometry and PEF monitoring in epidemiological studies on elderly respiratory patients
}

\author{
V. Bellia*, F. Pistelli", D. Giannini" ${ }^{\#}$ N. Scichilone*, F. Catalano*, M. Spatafora*, R. Hopps*, L. Carrozzi", \\ S. Baldacci ${ }^{\Uparrow}$, F. Di Pede ${ }^{\#}$, P. Paggiaro", G. Viegi
}

Questionnaires, spirometry and PEF monitoring in epidemiological studies on elderly respiratory patients. V. Bellia, F. Pistelli, D. Giannini, N. Scichilone, F. Catalano, M. Spatafora, R. Hopps, L. Carrozzi, S. Baldacci, F. Di Pede, P. Paggiaro, G. Viegi. (C) ERS Journals Ltd 2003.

ABSTRACT: Questionnaires are the most used subjective instrument of measurement in respiratory epidemiology. The standardisation of the questionnaires aims to limit bias by maximising validity and reliability, and comparability. Within the European Union project BIOMED1, a compendium of respiratory standard questionnaires (CORSQ) was developed for adults covering 18 topics from general information to early life events, through environmental risk factors and respiratory symptoms and diseases.

Reliable spirometry data needs a rigorous quality control programme, as in the "Salute Respiratoria nell'Anziano" (Sa.R.A.) project, Italian for "Respiratory Health in the Elderly". Reproducibility rates were $95.8 \%$ for forced expiratory volume in one second (FEV1). Male sex and age were independent risk factors for a poorer reproducibility, as well as cognitive and physical impairment (shorter 6-min walking distance) and lower educational level for a poorer acceptability. Reference values for people aged 65-85 yrs have been produced; these results suggest that the effect of aging should be corrected for physical and mental disability. A revision of interpretative strategies included in current guidelines is needed.

Peak expiratory flow monitoring has several methodological problems: reliability and sensitivity of the measurement in order to detect changes in airway calibre; compliance with long-term monitoring; choice of the best variability index; difference between asthmatic and nonasthmatic subjects; age-related differences. Despite these methodological problems, peak expiratory flow monitoring has been successfully used in the evaluation of the effects of air pollution in normal and asthmatic subjects, and in the elderly.

Eur Respir J 2003; 21: Suppl. 40, 21s-27s.
*Institute of Respiratory Diseases, University of Palermo, Palermo, and ${ }^{\#}$ Cardiothoracic Dept, University and Hospital of Pisa, and Pulmonary Environmental Epidemiology Group CNR, Institute of Clinical Physiology, Pisa, Italy.

Correspondence: V. Bellia

1st. di Medicina Generale e Pneumologia

Università degli Studi di Palermo

Fisiopatologia Respiratoria

Via Trabucco, 180

90146 Palermo

Italy

Fax: 390916882165

E-mail: vbellia@mbox.infcom.it

Keywords: Elderly

peak expiratory flow

questionnaires

reference values

spirometry

Received and accepted: April 122002
The problem of respiratory effects of pollutants in the elderly is rather new. Only recently, health authorities and professionals have become aware that, because of the demographic and cultural revolution of the last decades, not only the number of elderly subjects with or without respiratory diseases is increasing, but also the health expectancy and the demands of these subjects are increasing and becoming similar to those characterising younger adults. However, relatively little is known on the specific characteristics of the interaction between the environment and older lungs. In fact, a limited number of studies has been performed so far, and there is still uncertainty, as concerns the applicability to the elderly population, of conventional investigational methods validated for the use in younger cohorts. The aim of this contribution is a brief review of present knowledge concerning the most common instruments used in epidemiological surveys, i.e. questionnaires, spirometry and peak expiratory flow (PEF) monitoring.

\section{Questionnaires}

Questionnaires are the most commonly used subjective instrument of measurement in respiratory epidemiology.
They represent a convenient tool of investigating large population samples, due to low cost, ease of employment for the investigator, and good compliance of the investigated subject.

Validity and reliability express the quality of the data collected by questionnaires $[1,2]$. The comparison of the results of a questionnaire with separate and independent criteria assesses validity, which is expressed as sensitivity and specificity. The agreement of responses between two administrations of the same questionnaire, repeated after an adequate time interval, assesses reliability, which is expressed as consistency. The degrees of validity and reliability of the questionnaires may be reduced by bias, which may be due to the way of administration, recall of investigated information, etc. [1-3]. The standardisation of the questionnaires aims to limit bias by maximising validity and reliability [1-4].

The first standardised respiratory questionnaire was proposed by the British Medical Research Council [5]. It was first published in 1960 to investigate the epidemiology of chronic bronchitis and chronic airway obstruction, and subsequently has been revised $[6,7]$. It was used as a model for new questionnaires developed in the following years in Europe (e.g. the European Coal and Steel Community questionnaire $[8,9])$ and in the USA (e.g. the National Heart and Lung 
Institute (NHLI) questionnaire [10]; the American Thoracic Society (ATS) and NHLI Division of Lung Diseases (DLD) questionnaire (ATS-DLD-78 questionnaire) [11]; the Tucson (AZ, USA) epidemiological study questionnaires (Arizona questionnaires) [12, 13].

In $1960 \mathrm{~s}-1970 \mathrm{~s}$, the main focus of the research was on chronic bronchitis, emphysema, and chronic airway obstruction. Thus, questions mainly regarded respiratory symptoms such as cough, phlegm, and dyspnoea, while investigated risk factors were active tobacco smoking and occupational exposures. The questions were generally formulated to elicit information covering the lifetime of the investigated subject.

In the mid-1980s, research focused mainly on asthma as a cause of chronic respiratory disease. In order to find the most valid combination of questions on symptoms identifying asthmatic subjects, the International Union Against Tuberculosis and Lung Diseases Bronchial Symptoms Questionnaire was developed [14-16]. Two other standard questionnaires were developed within the European Community Respiratory Health Survey [17] and the International Study of Asthma and Allergies in Childhood [18].

The questionnaires mentioned above included extended items on asthma, asthma-like symptoms, and allergies. Questions mainly addressed respiratory symptoms, such as attacks of shortness of breath, wheezing, nocturnal cough, and chest tightness, while investigated risk factors were the use of medicines for asthma and indoor environmental conditions. The questions were generally formulated to elicit information covering the last 12 -month period of life of the investigated subject. More recent questionnaires include questions on outdoor and indoor environmental exposures, dietary habits, genetic influences, and quality of life [19-21].

In 1993-1996, a European Concerted Action entitled "Epidemiological surveys on chronic obstructive pulmonary disease in different European Countries: prevalence rates and relationship to host and environmental risk factors" (CACOPD) (Coordinator: C. Giuntini, University of Pisa, Italy) was carried out, under the contract BIOMED1 [22]. The CACOPD involved France, Italy, Norway, Sweden, The Netherlands, and the UK from Western Europe and, marginally, Albania, Estonia, Latvia, Romania, and Slovakia as PECO (Central-Eastern European) countries.

In order to elicit and compare variables of interest from the different European data sets, a small questionnaire on the type and extent of the existing data, and on methodological procedures used to collect them was filled in by the participating investigators. It showed that either modified versions of standard questionnaires or ad hoc questionnaires had been used in most surveys, instead of standard respiratory questionnaires.

Therefore, the idea emerged to generate a Compendium Of Respiratory Standard Questionnaires for adults (CORSQ) $[23,24]$, with the aim to make available a synthetic reference of a structured collection of standard questions, which could also be administered in respiratory epidemiological surveys or used to design new questionnaires in this field. CORSQ includes questions from the questionnaires used in the various studies performed by the CA-COPD research groups and from the most widely used European and American respiratory questionnaires, as well as new questions as proposals (see Appendix A). CORSQ covers 18 topics listed in Appendix B.

In conclusion, the questionnaires are a basic instrument in respiratory epidemiology. While a number of standardised questionnaires to investigate respiratory symptoms/diseases and risk factors have been developed, more recent topics (e.g. use of respiratory medicines, early life events, and daily activity pattern) need to be validated. The CORSQ is intended as a reference of existing validated questions, and as an example for possible new questions that can be used in respiratory epidemiology.

\section{Spirometry}

\section{General aspects}

Since its introduction in clinical practice, measurements of lung volumes and related indices have played a central role in the objective assessment of most respiratory diseases. Among various parameters, forced expiratory volume in one second (FEV1) is strongly recommended as an index of choice for the following reasons: 1) it is reproducible, in most instances with a well-defined range of variation accounting for age, sex and ethnic group; 2) it has a strong prognostic value in some very important diseases, such as chronic obstructive pulmonary disease (COPD) [25, 26]; actually, lung function testing is recognised as a measure of global health, predicting all-cause mortality [27, 28], even in the long-term [29]; 3) in addition, serial measurements allow for the follow-up of physiological decline of ventilatory function, as well as the monitoring of the progression of obstructive and restrictive pulmonary diseases and the response to treatments.

In this perspective, its importance in epidemiological studies cannot be overemphasised. Nevertheless, spirometry is not yet extensively used, at least in some subpopulations such as elderly patients. In fact, it is often assumed that, because of the cognitive and physical impairment frequently associated with the aging process, such subjects are unable to perform the demanding activities needed to obtain reliable spirometric measurements. However, objective and quantitative methods for the evaluation of functional impairment are particularly needed in epidemiological studies concerning elderly cohorts, since in these subjects the reliability of clinical assessment, including the related methodology of questionnaires, may be limited for the following reasons: 1) aging is accompanied by a progressive and general reduction of sensitivity to stimuli that, among others, affects respiratory stimuli and, in particular, those related to breathlessness; 2) standard lifestyle of elderly subjects is usually sedentary and the occasions for performing physical efforts are reduced, so that the awareness of an exercise limitation may be blunted; 3 ) the frequent condition of comorbidity, with a special reference to cardiovascular diseases, may confound the clinical presentations.

\section{Applicability of spirometry in the geriatric population}

In order to obtain useful information from the spirometric test, both adequate equipment and proper performance are requested. It is now well recognised that the largest single source of within-subject variability is improper performance of the test. Therefore, international guidelines have been published that include detailed indications for the standardisation of equipment and performance. However, in some subpopulations, like the geriatric one, this experience is scanty. In fact, the vast majority of studies have included only small numbers of elderly subjects, if any. Therefore, until recently, the specific characteristics of the older subjects have been ignored. The application of conventional criteria, validated only in younger adults, has led to a significant proportion of failures represented either by the inability to perform manoeuvres or by the lack of acceptability or reproducibility of measures. Major reservations concern the physical and cognitive aspects of procedures. Actually, maximum spirometric manoeuvres are unusual activities, to which the elderly 
subject is unaccustomed. In addition, they are physically demanding both from the point of view of respiratory muscles and of the rib cage-lung system. High-quality spirometry requires a good cooperation between the patient and the technician, the ability to learn and recall instructions by the patient, as well as physical cooperation, which are not easily found in the geriatric population. To a certain extent, all elderly individuals undergo a physical and intellectual decline; these phenomena may be particularly evident in respiratory patients, such as the COPD ones, where a reliable assessment of respiratory function is particularly needed.

One of the earliest studies is by MiLNE and WiLLIAMSON [30], who investigated a sample of subjects aged $\geqslant 62 \mathrm{yrs}$. It was observed that the percentage of elderly females unable to perform spirometry increased with age and correlated with the diagnosis of dementia [30]. The role of cognitive deficit has been confirmed by SHERMAN et al. [31] on 65 ambulatory subjects aged $>65$ yrs. While $\sim 90 \%$ were able to perform spirometry, eight of them $(12.3 \%)$ were unable to perform at least three acceptable forced vital capacity (FVC) manoeuvres requested by the ATS standard procedures. These subjects reached the lowest scores in tests aimed at evaluating executive function and psychomotor velocity. Conversely, their score at the Mini Mental State Examination (MMSE), although lower $(23.7 \pm 4.6$ versus $26.5 \pm 2.5)$, was not significantly different from that measured in subjects able to perform a good spirometry. In the same study, 18 subjects (31.6\%) were unable to meet the ATS reproducibility criteria for FEV1, FVC or both. Regarding acceptability, only nine patients $(15.8 \%)$ showed a 2 -s end-expiratory plateau, with an exhalation time of $\geqslant 6 \mathrm{~s}$. However, this result was not correlated to any cognitive deficit, but was rather interpreted as related to an age-related reduction in lung elastic recoil.

Later, other large studies have demonstrated the full applicability of the method to populations of elderly subjects with better preserved mental and physical conditions. This was the case of the normative investigation carried out within the context of the Cardiovascular Health Study. Only 145 elderly subjects out of $>5,000$ proved unable to perform at least three acceptable and reproducible manoeuvres [32]. The feasibility of high-quality spirometry in elderly subjects and the role of cognitive and physical impairment have recently been confirmed in a large population of 1,612 ambulatory subjects aged $\geqslant 65 \mathrm{yrs}$, with and without chronic airflow obstruction, recruited within the context of the multicentre case-control "Salute Respiratoria nell'Anziano" (Sa.R.A.) study (Italian for "Respiratory Health in the Elderly") carried out in Italy [33]. The study demonstrates that, when a rigorous quality control programme is established, highly reproducible spirometric measurements may be obtained. Percentages of reproducible tests ranged from $87.6 \%$ for $\mathrm{FVC}$ in patients to $95.8 \%$ for FEV1 in controls. Tests with at least three acceptable curves were $83.6 \%$ in cases and $81.9 \%$ in controls. Along with cognitive impairment, lower educational level and shorter 6-min walking distance were found to be independent risk factors for a poorer acceptability rate; male sex and age were risk factors for a poorer reproducibility of FEV1.

It must be emphasised that such results cannot be reliably expected in the general population of aged patients, characterised by a wider range of limitations. The relationship between mental deterioration and poor spirometric performance is confirmed by a study carried out on a different type of sample. Institutionalised patients aged 65-102 yrs $(n=208)$ were recruited in a long-term care hospital; 126 scored $\leqslant 17$ at MMSE, corresponding to a severe cognitive deficit, and 36 $(17.3 \%)$ scored $18-24$, indicating a mild impairment [34]. Of the 208 patients, only $85(40.9 \%)$ were able to perform spirometry; in particular, the percentage was as high as $78.3 \%$ in subjects with no evidence of impairment (MMSE not <24).
The success rate dropped to $19 \%$ in subjects showing a severe impairment of cognitive function. In the same sample, applicability of respiratory impedance measurements by forced oscillation technique has been tested as an alternative method, comparing favourably with spirometry from the point of view of less stringent need of collaboration from the patient. With this method, acceptable tests were obtained in 159 patients (76.4\%); the result is significantly higher than that obtained with spirometry.

The relationship between spirometry and cognitive capacity has been explored in a different and original perspective by CHYOU et al. [35]. Between 1991-1993, CHYOU et al. [35] studied a cohort of 3,036 Japanese-American subjects aged $>70 \mathrm{yrs}$, who at least 23 yrs before (1965-1968) had been submitted to spirometric examination. The study was aimed at evaluating retrospectively to what extent spirometric data may allow to predict the decline in cognitive function. Multiple regression analysis demonstrated that FEV1 measured during middle age was a significant predictor of intellectual decline in later life, independently of age, occupation and other clinical, functional and cultural variables.

\section{Reference values}

Given the relationship between lung volumes and body size, the interpretation of spirometric results must be done with reference to predictive values derived from healthy populations. It is generally agreed that there is not a set of standard reference values good for all seasons and that it is important to ensure that the reference equations are applicable to the patient population being tested. For this reason, ATS recommends that subjects used in reference studies should be representative of the population from which patients will be derived [36]. Accordingly, most available reference equations for spirometry should not be used in older subjects, since the samples from which they derive include relatively small numbers of individuals $>65$ yrs of age. Only recently, ENRIGHT et al. [32] have published new prediction equations derived from a reference population of 777 subjects aged 65-85 yrs. By comparing these results with those derived from the application of the most commonly used equations, ENRIGHT et al. [32] demonstrated differences, as great as $20 \%$, in the predicted values. In addition, several nonrespiratory medical conditions that may independently, significantly and negatively affect FEV1 in elderly subjects were identified. These include systolic hypertension, diastolic hypotension, major electrocardiogram abnormalities, diabetes, and being over- and underweight. The importance of using prediction equations appropriate to the ethnicity, even in the geriatric setting, is emphasised in a study concerning Japanese-American males aged 71-90 yrs [37]. In this perspective, a set of reference values relevant to healthy elderly subjects of Italian descent has been provided by the cited Sa.R.A. study carried out on 429 subjects aged $65-100$ yrs, who had smoked $<5$ packs $\cdot \mathrm{yr}^{-1}$ [38]. In this study, the analysis of the interaction of usual predictors with some indicators of disability suggests that the effect of ageing on spirometric variables should be corrected for the level of physical and mental disability.

\section{Peak expiratory flow}

PEF monitoring has frequently been used to assess the effects of different factors (including air pollutants) on airway calibre. The method is easy to perform, inexpensive and well tolerated. It also allows for the collection of a large number of measurements during the day and for several days, in relation to different trigger factors. 


\section{Technical considerations}

The linearity and the accuracy of different PEF meters (PFM) have been extensively evaluated, showing in general a high reproducibility and repeatability of the measures [39]. However, many instruments do not show linear responses, with different proportional error at different flow levels [40]. This phenomenon can be corrected by new models using a nonlinear scale [41]. A significant decrease in the relative accuracy and precision can be observed after regular PFM use [41]. It is recommended that a given PFM should be capable of generating accurate flows between $0-900 \mathrm{~L} \cdot \mathrm{min}^{-1}$ and yield readings within $10 \%$ or $10 \mathrm{~L} \cdot \mathrm{min}^{-1}$ of the true value [42]. The repeatability (within-instrument agreement) should be $3 \%$ or $10 \mathrm{~L} \cdot \mathrm{min}^{-1}$, whichever is greater, and the reproducibility should be within $5 \%$ or $20 \mathrm{~L} \cdot \mathrm{min}^{-1}$.

\section{Relationship between peak expiratory flow and forced expiratory volume in one second}

FEV1 and PEF are both obtained from the forced expiratory manoeuvre. But, while PEF is measured on the first effort-dependent portion of the forced expiratory manoeuvre, FEV1, which represents the "gold standard" in the measurement of airway obstruction, reflects airway resistance at different sites in the airways. Therefore, FEV1 and PEF are not interchangeable. PEF is not able to assess bronchodilator response compared to FEV1 $(\triangle \mathrm{PEF}$ of $\geqslant 10 \%, \geqslant 15 \%, \geqslant 20 \%$ baseline has a positive predicting value of $36 \%, 52 \%$, and $67 \%$, respectively for $\Delta \mathrm{FEV} 1 \geqslant 9 \%$ pred) [43]. During acute bronchoconstriction induced by different stimuli in the laboratory, the concordance (Cohen's weighted kappa) between classes of changes in FEV1 and PEF was low (0.28-0.42 in different challenges) [44]. The sensitivity of PEF in detecting mild, induced bronchoconstriction was lower than FEV1, with a $10 \%$ change in PEF resulting in a $15 \%$ change in FEV1 (fig. 1) [44].

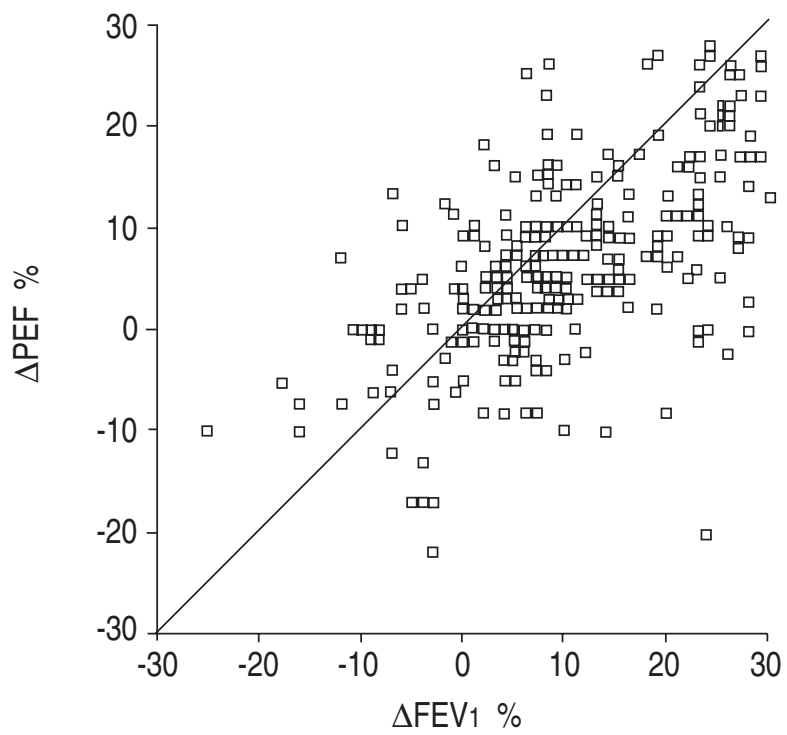

Fig. 1.- Linear regression between per cent change of forced expiratory volume in one second (FEV1) and peak expiratory flow (PEF) from baseline value at different time points during allergen-induced bronchoconstriction. Positive values indicate a decrease in FEV 1 and PEF after challenge. Identity line is shown.

\section{Compliance}

In the clinical setting, several studies have shown that both occupational and nonoccupational asthmatics falsify a large percentage $(20-50 \%)$ of reported measurements $[45,46]$. The compliance tended to decrease with time, reaching a plateau after 1 month. Thus, 1 or 2 weeks of PEF monitoring may be an adequate time interval to obtain a satisfactory adherence. High numbers of daily measurements (e.g. every $2 \mathrm{~h}$ during waking hours to obtain better indices of PEF variability [47]) reduce compliance. Two measurements daily, commonly utilised during clinical trials, are better tolerated than four or more, and permit the differentiation of normal circadian variation of airway calibre from pathological variation.

\section{Indices of peak expiratory flow variability}

Analysis of PEF variability is frequently performed by means of visual analysis of graphs obtained using the raw data; however, this method does not allow for objective criteria to be obtained. Various indices of PEF variability have been computed to differentiate patients from normal subjects, without the bias of inter- and intra-observer variability. Indices of intra-day variability (coefficient of variation (CV); maximal amplitude (MA) \% mean; morning dip) and indices of day-to-day variability (CVs of all measurements at the same time of the day: CV-Morning or CV-Bed) can be obtained by a computerised program of analysis of raw data [48]. Most of these indices can be used to distinguish normal from asthmatic subjects [40]. REDDEL et al. [49] indicated the minimum morning prebronchodilator PEF over a week (expressed as per cent of the recent personal best value) as a very simple and effective index, and SIERSTED et al. [50] demonstrated that the two lowest \% index (mean of lowest two readings in the period/period mean $\times 100$ ) can identify $28 \%$ of symptomatic asthmatics versus $19.2 \%$ identified by $\mathrm{MA} \%$ mean. These techniques can significantly increase the ability of PEF in separating normal from asthmatic symptomatic subjects.

\section{Peak expiratory flow, bronchial hyperresponsiveness and symptoms}

In asthma epidemiology, PEF variability has been suggested as an alternative to bronchial hyperresponsiveness (BHR) [51]. However, in clinical practice the relationships between symptoms, BHR, and PEF variability are more complex. GOLDSTEIN et al. [52] did not find any significant correlations between indices of PEF variability and BHR, while BHR had higher sensitivity and negative predicted value than did PEF variability. Monitoring of PEF variability alone is not able to identify the deterioration in FEV1 as well as the provocative dose of histamine causing a $20 \%$ fall in FEV1 in patients on long-term inhaled corticosteroids, and the increase in symptom score is not always related to an increase in PEF variability [53]. Similar poor correlation is found when, within each subject, PEF variability and BHR are correlated longitudinally [54]. Thus, PEF variability may represent something different from symptoms and BHR, and PEF evaluation may be helpful in optimising asthma control. However, CHAN-Yeung et al. [55] demonstrated that acute asthma exacerbations occur before any significant decrease $(\geqslant 30 \%)$ in PEF from the patient's best reading or significant increase in daily variation PEF from the baseline can occur. 


\section{Difference in peak expiratory flow measurement with age}

In an elderly population, PEF, as a single measurement, was significantly related to age, sex, smoking, functional ability and physical activity [56], and, after adjustment for these variables, it was a highly significant predictor of 5-yr total mortality [57]. In a random sample of elderly subjects, respiratory symptoms, cardiac disease or being overweight were all associated with higher PEF variability, and absolute PEFs were lower and PEF variability was higher in the older age groups [58]. BELLIA et al. [59] demonstrated that older asthmatics (age: 53-74 yrs) had greater PEF variability than younger asthmatics (age: 14-47 yrs), while they were similar for severity of symptoms and pulmonary function (fig. 2). As a result, aged patients are potentially at risk because functional abnormalities can be accompanied by a poor subjective awareness.

Peak expiratory flow in assessing the effect of air pollution

Several studies have demonstrated a relationship between air pollutant levels and changes in respiratory symptoms and function (including peak expiratory flow variability) both in the general population and in selected groups of asthmatic
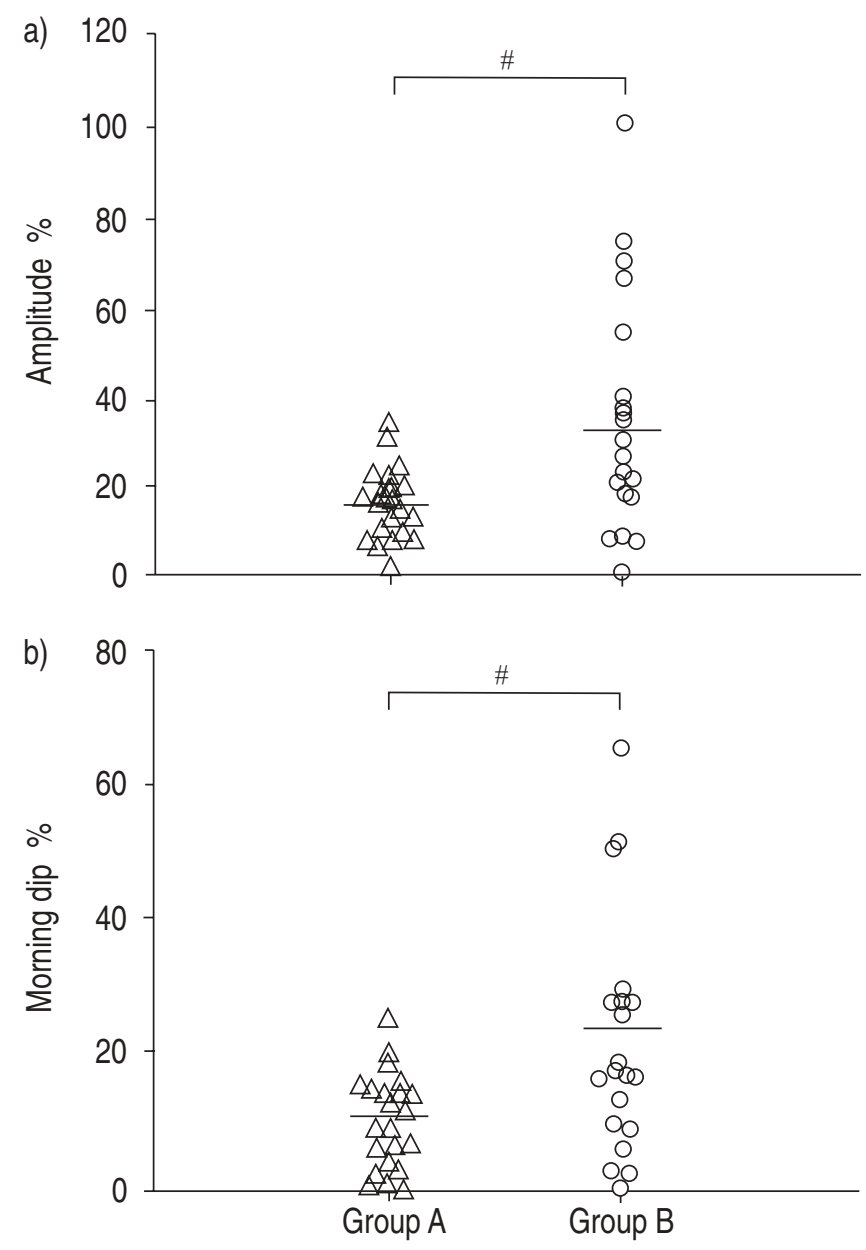

Fig. 2.-Mean individual values for a) amplitude of variation and b) morning dip. The horizontal bars indicate the mean group values. The differences between means were significant both for amplitude and morning dip. Group A $(\triangle)$ : younger patients; Group B $(\bigcirc)$ : older patients. ${ }^{\#}: \mathrm{p}<0.005$. subjects [60]. The sensitivity of peak expiratory flow monitoring in comparison with other markers of negative effect on the airways has not yet been established. Very few studies have been conducted on elderly populations. However, one such study by VAN DER ZEE et al. [61] demonstrated that, in a large sample of 50-70-yr-old subjects, decrements in morning peak expiratory flow were associated with airborne concentrations of several pollutants.

\section{Appendix A: Respiratory questionnaires referenced in the Compendium of Respiratory Standard Questionnaires for adults (CORSQ)}

1. Italian Research Council (CNR) questionnaire on respiratory symptoms, diseases and risk factors, used in the Po River Delta and Pisa study [62].

2. Questionnaire of the European Community for Coal and Steel (ECCS) on respiratory symptoms 1987: updating of the 1962 and 1967 questionnaire for studying chronic bronchitis and emphysema [9].

3. Questionnaire used in the European Commission Respiratory Health Survey (ECRHS) [17].

4. Adult questionnaire used in the Arizona Tucson Epidemiologic Study of Obstructive Lung Diseases (Eighth Survey) [13].

5. Adult questionnaire used in the Arizona Tucson Epidemiologic Study of Obstructive Lung Diseases (Eleventh Survey) [13].

6. Questionnaire used in the Obstructive Lung Disease in Northern Sweden study (OLIN) (1992 version) [63].

7. Questionnaire used in the investigation into the occurrence of allergies, asthma and other lung diseases in Hordaland (1985 version) [64].

8. Medical Research Council's (MRC) Committee on Environmental and Occupational Health Questionnaire on respiratory symptoms, 1986 [7].

9. International Union Against Tuberculosis (IUAT) bronchial symptoms questionnaire, 1986 [16].

10. American Thoracic Society - Division of Lung Diseases, National Heart, Lung, and Blood Institute 1978 (ATSDLD-78) questionnaire [11].

11. Questionnaire familial, Etude épidémiologique des facteurs génétiques et environnementaux de l'asthme, l'hyperréactivité bronchique et l'atopie (EGEA) [20].

12. Questionnaire used in the Cooperative European AntiSmoking Evaluation (CEASE) trial, 1994 [65].

13. Questionnaire used in the Pollution Effects on Asthmatic Children in Europe (PEACE) study [66].

14. The St. George's Respiratory Questionnaire, 1991 [67].

\section{Appendix B: List of the topics of the Compendium of Respiratory Standard Questionnaires for adults (CORSQ)}

General information

Familial diseases

General diseases

Respiratory diseases

Respiratory symptoms

Allergic symptoms

Active smoking

Passive smoking

Occupational history

Environmental conditions

Social and economic conditions

Diet 
Physical activity

Daily activity pattern

Use of respiratory medicines

Use of health services

Health status and quality of life

Early life events

\section{References}

1. Samet JM. A historical and epidemiologic perspective on respiratory symptoms questionnaires. Am J Epidemiol 1978; 108: 435-446.

2. Commission of the European Communities. DirectorateGeneral XII for science, research and development. Cost 613/ 2 Report Series on Air Pollution Epidemiology. Brunekeef B, ed. Report No. 2. Health Effect Assessment. Brussels, Commission of the European Communities, 1992, pp. 45-53.

3. Armstrong BK, White E, Saracci R. Methods of exposure measurement. In: Kelsey JL, Marmot MG, Stolley PD, Vessey Martin PV, eds. Principles of Exposure Measurement in Epidemiology. Monographs in Epidemiology and Biostatistics. Vol. 21. Oxford, Oxford University Press, 1992; pp. 22-48.

4. Liard R, Neukirch F. Questionnaires: a major instrument for respiratory epidemiology. Eur Respir Mon 2000; 15: 154-166.

5. Medical Research Council, Committee on the Aetiology of Chronic Bronchitis. Standardized questionnaire on respiratory symptoms. $\mathrm{Br}$ Med $J$ 1960; 2: 1665.

6. Holman WJ, Dawlish, Devon, eds. Medical Research Council's Committee on Research into Chronic Bronchitis. A) Questionnaire on respiratory symptoms; B) Instructions for the use of the questionnaires on respiratory symptoms. London, Medical Research Council, 1966.

7. Medical Research Council's Committee on Environmental and Occupational Health. Questionnaire on respiratory symptoms. London, Medical Research Council, 1986.

8. Brille D, Bolt W, Greve LH, Minette A, Sartorelli E. European Coal and Steel Community (ECSC): high authority questionnaire on the study of chronic bronchitis and emphysema. Luxembourg, ECSC, 1962.

9. Minette A. Questionnaire of the European Community for Coal and Steel (ECSC) on respiratory symptoms: 1987 updating of the 1962 and 1967 questionnaires for studying chronic bronchitis and emphysema. Eur Respir $J$ 1989; 2: $165-177$.

10. US Department of Health, Education and Welfare. Proceedings, First National Heart and Lung Institute Epidemiology Workshop. Washington DC, US Government Printing Office, 1971.

11. Ferris BG. Epidemiology Standardization Project. II. Recommended respiratory disease questionnaires for use with adults and children in epidemiological research. Am Rev Respir Dis 1978; 118: 7-57.

12. Lebowitz MD, Knudson RJ, Burrows B. Tucson epidemiologic study of obstructive lung diseases: I. Methodology and prevalence of disease. Am J Epidemiol 1975; 102: 137-152.

13. Lebowitz MD, Burrows B. Comparison of questionnaires: the BMRC and NHLI respiratory questionnaires and a new self-completion questionnaire. Am Rev Respir Dis 1976; 113: 627-635.

14. Burney PJG, Chinn S. Developing a new questionnaire for measuring the prevalence and distribution of asthma. Chest 1987; 91: Suppl. 6, 79s-83s.

15. Burney PGJ, Laitinen LA, Perdrizet S, et al. Validity and repeatability of the IUATLD (1984) Bronchial Symptoms Questionnaire: an international comparison. Eur Respir $J$ 1989; 2: 940-945

16. Torén K, Brisman J, Järvholm B. Asthma and asthma-like symptoms in adults assessed by questionnaires. A literature review. Chest 1993; 104: 600-608.
17. Burney PGJ, Luczynska C, Chinn S, Jarvis D. The European Community Health Survey. Eur Respir J 1994; 7: 954-960.

18. Asher MI, Keil U, Anderson HR, et al. International Study of Asthma and Allergies in Childhood (ISAAC): rationale and methods. Eur Respir J 1995; 8: 483-491.

19. Riboli E, Kaaks R. The EPIC Project: rationale and study design. European Prospective Investigation into Cancer and Nutrition. Int J Epidemiol 1997; 26: Suppl. 1, S6-S14.

20. Kauffmann F, Dizier MH. EGEA (Epidemiological study on the Genetics and Environment of Asthma, bronchial hyperresponsiveness and atopy) - design issues. EGEA Co-operative Group. Clin Exp Allergy 1995; 25: Suppl. 2, 19-22.

21. Jones PW, Quirk FH, Baveystock CM, Littlejohns P. A selfcompleted measure of health status for chronic airflow limitation - the St. George's Respiratory Questionnaire. Am Rev Respir Dis 1992; 145: 1321-1327.

22. Giuntini C, Viegi G. Epidemiologic determinants of COPD in some European Countries. Eur Respir Rev 2001; 11: 80.

23. Pistelli F, Viegi G, Carrozzi L, Rönmark E, Lundbäck B, Giuntini G. Usefulness of a compendium of respiratory standard questionnaires for adults (CORSQ). Eur Respir Rev 2001; 11: 80, 98-102.

24. Pistelli F, Viegi G, Carrozzi L, Rönmark E, Lundbäck B, Giuntini G. Appendix 3: Compendium of respiratory standard questionnaires for adults (CORSQ). Eur Respir Rev 2001; 11: 80, 118-143.

25. Peto R, Speizer FE, Cochrane AL, et al. The relevance in adults of airflow obstruction, but not of mucus hypersecretion to mortality from chronic lung disease. Am Rev Respir Dis 1983; 128: 491-500.

26. Thomason MJ, Strachan DP. Which spirometric indices best predict subsequent death from chronic obstructive pulmonary disease. Thorax 2000; 55: 785-788.

27. Weiss ST, Segal MR, Sparrow D, Wager C. Relation of FEV1 and peripheral blood leukocyte count to total mortality. The Normative Aging Study. Am J Epidemiol 1995; 142: 493-498.

28. Hole DJ, Watt GC, Davey-Smith G, Hart CL, Gillis CR, Hawthorne VM. Impaired lung function and mortality risk in men and women: findings from the Renfrew and Paisley prospective population study. BMJ 1996; 313: 711715.

29. Schunemann HJ, Dorn J, Grant BJB, Winkelstein W Jr, Trevisan M. Pulmonary function is a long-term predictor of mortality in the general population. Chest 2000; 118: 656664.

30. Milne JS, Williamson J. Respiratory function tests in older people. Clin Sci 1972; 42: 371-381.

31. Sherman CB, Kern D, Richardson ER, Hubert M, Fogel BS. Cognitive function and spirometric performance in the elderly. Am Rev Respir Dis 1993; 148: 123-126.

32. Enright PL, Kronmal RA, Higgins M, Schenker M, Haponik EF. Spirometric reference values for women and men 65 to 85 years of age. Cardiovascular health study. Am Rev Respir Dis 1993; 147: 125-133.

33. Bellia V, Pistelli R, Catalano F, et al. Quality control of spirometry in the elderly. The SA.R.A. study. Am J Respir Crit Care Med 2000; 161: 1094-1100.

34. Carvalhaes-Neto N, Lorino H, Gallinari C, et al. Cognitive function and assessment of lung function in the elderly. Am J Respir Crit Care Med 1995; 152: 1611-1615.

35. Chyou P-H, White LR, Yano K, et al. Pulmonary function measures as predictors and correlates of cognitive functioning in later life. Am J Epidemiol 1996; 143: 750-756.

36. American Thoracic Society. Lung function testing: selection of reference values and interpretative strategies. Am Rev Respir Dis 1991; 144: 1202-1218.

37. Sharp DS, Enright PL, Chiu D, Burchfield CM, Rodriguez BL, Curb D. Reference values for pulmonary function tests of Japanese-American men aged 71 to 90 years. Am J Respir Crit Care Med 1996; 153: 805-811.

38. Pistelli R and SA.R.A. study group. Reference equations for 
spirometric variables in elderly Italian subjects: the SA.R.A. study. Eur Respir J 1999; 14: 292s-293s.

39. Miller MR, Dickinson SA, Hitchings DJ. The accuracy of portable peak flow meters. Thorax 1992; 47: 904-909.

40. Paggiaro PL, Moscato G, Giannini D, et al. The Italian Working Group on the use of peak expiratory flow rate (PEFR) in asthma. Eur Respir Rev 1993; 314, 438-443.

41. Irvin CG, Martin RJ, Chinchilli VM, Kunselman SJ, Cherniack RM and and the Asthma clinical research network (ACRN). Quality control of peak flow meters for multicenter clinical trials. Am J Respir Crit Care Med 1997; 156: $396-402$.

42. American Thoracic Society. Standardization of spirometry: 1994 update. Am J Respir Crit Care Med 1995; 152: 11071136.

43. Thiadens HA, De Bock GH, Van Houwelingen, et al. Can peak expiratory flow measurements reliably identify the presence of airway obstruction and bronchodilator response as assessed by FEV1 in primary care patients presenting with a persistent cough? Thorax 1999; 54: 1055-1060.

44. Giannini D, Paggiaro PL, Moscato G, et al. Comparison between peak expiratory flow and forced expiratory volume in one second (FEV1) during bronchoconstriction induced by different stimuli. J Asthma 1997; 34: 105-111.

45. Malo JL, Trudeau C, Ghezzo H, L'Archeveque J, Cartier A. Do subjects investigated for occupational asthma through serial peak expiratory flow measurements falsify their results? J Allergy Clin Immunol 1995; 96: 601-607.

46. Verschelden P, Cartier A, L'Archeveque J, Trudeau C, Malo JL. Compliance with and accuracy of daily self-assessment of peak expiratory flows (PEF) in asthmatic subjects over a three month period. Eur Respir J 1996; 9: 880-885.

47. Venables KM, Burge PS, Davison AG, Newman Taylor AJ. Peak flow rate records in surveys: reproducibility of observers' reports. Thorax 1984; 39: 828-832.

48. Di Pede F, Paggiaro PL, Viegi G, et al. "PEAK": sistema computerizzato di archiviazione ed analisi delle misure del picco di flusso espiratorio. Limiti di normale variabilità. Giorn It Allergol Immunol Clin 1993; 3: 303-310.

49. Reddel KH, Salome CM, Peat JK, Woolcock AJ. Which index of peak expiratory flow is most useful in the management of stable asthma?. Am J Respir Crit Care Med 1995; 151: $1320-1325$.

50. Siersted HC, Hansen HS, Hansen NCG, Hyldebrant N, Mostgaard G, Oxhoj H. Evaluation of peak expiratory flow variability in an adolescent population sample. Am J Respir Crit Care Med 1994; 149: 598-603.

51. Higgins BG, Britton JR, Chinn S, Cooper S, Burney PGJ, Tattersfield AE. Comparison of bronchial reactivity and peak expiratory flow variability measurements for epidemiological studies. Am Rev Respir Dis 1992; 145: 588-593.

52. Goldstien MF, Veza BA, Dunsky EH, Dvorin DJ, Belecanech GA, Haralabatos IC. Comparison of peak diurnal flow variation, postbronchodilator FEV1 responses, and methacholine inhalation challenges in the evaluation of suspected asthma. Chest 2001; 119: 1001-1010.

53. Brand PLP, Duiverman EJ, Waalkens HJ, van EssenZandvliet EEM, Kerrebijn KF and and the Dutch CNSLD
Study group. Peak flow variation in childhood asthma: correlation with symptoms, airway obstruction, and hyperresponsiveness during long term treatment with inhaled corticosteroids. Thorax 1999; 54: 103-107.

54. Douma WR, Kerstjens HAM, Roos CM, Koeter GH, Postma DS, and the Dutch Chronic non-specific Lung Disease study group. Changes in peak expiratory flow indices as a proxy for changes in bronchial hyperresponsiveness. Eur Respir J 2000; 16: 220-225.

55. Chan-Yeung M, Chang JH, Manfreda J, Ferguson A, Becker A. Changes in peak flow, symptoms score, and the use of medications during acute exacerbations of asthma. Am J Respir Crit Care Med 1996; 154: 889-893.

56. Cook NR, Evans DA, Scherr PA, et al. Peak expiratory flow rate in an elderly population. Am J Epidemiol 1989; 130: 6678 .

57. Cook NR, Evans DA, Scherr PA, Speizer FE, Taylor JO, Hennekens $\mathrm{CH}$. Peak expiratory flow rate and 5-year mortality in an elderly population. Am J Epidemiol 1991; 133: 784-794.

58. Boezen HM, Rijcken B, Schouten JP, Postma DS. Breathlessness in elderly individuals is related to low lung function and reversibility of airway obstruction. Eur Respir J 1998; 12: $805-810$

59. Bellia V, Cuttitta G, Cibella F, et al. Effect of aging on peak expiratory flow variability and nocturnal exacerbations in bronchial asthma. Eur Respir J 1997; 10: 1803-1808.

60. Brunekreef B, Dockery DW, Krzyzanowski M. Epidemiological studies on short-term effects of low levels of major ambient air pollution components. Envir Health Perspect 1995; 103: Suppl. 2, 3-13.

61. Van der Zee SC, Hoek G, Boezen MH, Schouten JP, van Wijnen JH, Brunekreef B. Acute effects of air pollution on respiratory health of 50-70-yr-old adults. Eur Respir $J$ 2000; 15: 700-709.

62. Viegi G, Paoletti P, Prediletto R, et al. Prevalence of respiratory symptoms in an unpolluted area of Northern Italy. Eur Respir J 1988; 1: 311-318.

63. Lundback B, Sjernberg N, Nystrom L, Lundback K, Lindstrom M, Rosenhall J. An interview study to estimate prevalence of asthma and chronic bronchitis. The Obstructive Lung Disease in Northern Sweden Study. Eur $J$ Epidemiol 1993; 9: 123-133.

64. Bakke P, Gulsvik A, Lilleng P, Overa O, Hanoa R, Eide GE. Postal surveys on airborne occupational exposure and respiratory disorders in Norway: causes and consequences of non-response. J Epidemiol Community Health 1990; 44: 316-320.

65. P Tønnesen P, Paoletti P, Gustavsson G, et al. Higher dosage nicotine patches increase one-year smoking cessation rates: results from the European CEASE trial. Eur Respir J 1999; 13: $238-246$.

66. Roemer W, Hoek G, Brunekreef B. Pollution effects on asthmatic children in Europe, the PEACE study. Clin Exp Allergy 2000; 30: 1067-1075.

67. Jones PW, Quirk FH, Baveystock CM. The St George's Respiratory Questionnaire. Respir Med 1991; 85: Suppl. B, 25-31. 